\title{
Dental DNA Finger printing
}

\author{
Michael AB Naafs* \\ International Health Consultancy, Dutch Internist Endocrinologist, Netherlands
}

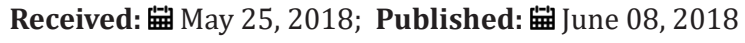

*Corresponding author: Michael AB Naafs, Dutch Internist Endocrinologist, Health Consultant at Naafs,International Health Consultancy, Rhodoslaan 20, 7577KN, Oldenzaal, Netherlands

\begin{abstract}
DNA fingerprinting has revolutionized the concept of identification Although clinical observation of available medical and dental patient records remain the gold standard for forensic pathology,dental DNA fingerprinting is booming in forensic science.The evolution of DNA fingerprinting techniques is discussed in this mini-review with a special emphasis to forensic odontology.

Keywords: Dna Fingerprinting; Molecular Level; Consanguinity; Paternity; Forensic Odontology; Polymerase Chain Reaction; Radiological Identification; High Molecular Weight; Single Locus Probing; Multiple-Locus Probing
\end{abstract}

\section{Introduction}

Molecular biology developed when it was realized that DNA lies behind all the cell's activities.The development of methods and techniques to study processes at the molecular level has led to new and powerful ways of isolating,manipulating and exploiting nucleic acids.DNA fingerprinting is the result of such an endeavor. This technique is mostly known by its application in forensic medicine,but is also used in transplant medicine, in the search of heriditary disorders,consanguinity,paternity, and in anthropology $[1,2]$. The role of dental restorations, prosthesis and radiological identification as the main stray of forensic odontology has declined lately,whereas molecular biology and laboratory procdures are rapidly increasing in efficiency and availability [3]. The tooth is the most valuable source to extract DNA since it is a sealed box preserving DNA from extreme environmental conditions,except its apical entrance. Teeth has been the subject of DNA studies as the dental hard tissue physically encloses the pulp and offers an anatomical configuration of great durability [4]. Moreover,even a single tooth provides valuable information regarding the individual to whom the tooth belongs [5-7]. In this mini-review dental DNA fingerprinting and its applications will be discussed.The applications in health and medicine and in anthropolgy are beyond the scope of this mini-review.

\section{History}

Jeffery described in 1985 hypervariable regions of human DNA using multilocus probes and the applicability of these DNA polymorphisms to the indivdualization of human blood and tissues [8]. The potential forensic application was immediately recognized [9]. Polymerase chain reaction which was originally described by Saiki et al. and subsequently automated by Mullis and Falcona,has emerged as a powerful tool in forensics for the exponential in vitro amplification of specific sequences of interest from "minute'quantities of DNA or RNA and was applied to forensic odontology $[10,11]$. Schwartz isolated high molecular weight (HMW) DNA from the teeth under different environmental conditions such as varying $\mathrm{pH}$,humidity,temperature,storage, etc.It was determined that the environmental conditions did not affect the ability to obtain HMW human DNA from dental pulp [12]. Pötsch performed genomc dot blot hybridization for sex determination using the botinylated repetetive DNA probe pHY2.1 and sex was correctly classified in all cases using 50-100 ng target DNA from dental pulp [3]. Sweet and Sweet, a case of human remains identification by a preserved unerupted third molar which enabled 1,35ug DNA from the pulp $[13,14]$.

\section{How does it work?}

a) Making DNA fingerprints is a laboratory procedure that requires 6 steps [1]. Isolation of DNA; DNA must be removed from the cells or tissues of the body.Only a small amount of tissue e.g. dental pulp is needed.

b) Cutting,sizing and sorting,Special enzymes called restriction enzymes are used to cut the DNA at specific places.For example,an enzyme called EcoR1,found in E coli bacteria, will cut DNA only when the sequence GAATTC occurs 
(guanine,adenine,adenine,thymine,thymine,cytosine) The DNA pieces are sorted according to size by a sieving technique called electrophoresis.The DNA pieces are passed through a gel made from seaweed agarose (Southern blot).This technique is the biotechnology equivalent of screening sand through progressively finer mesh screens to determine particle sizes.

c) Transfer of DNA to nylon; The distribution of DNA pieces is transfered to a nylon sheet by placing the sheet on the gel and soaking them overnight.

d) Probing;Adding radioactive or colored probes tothe nylon sheet produces a pattern called the DNA fingerprint. Each probe typically sticks in only one or two specific places on the nylon sheet.

e) DNA fingerprint, The final DNA fingerprint is built by using several probes (5-10 or more) simultaneously. It resembles the bar codes used by grocery scanners. The final product of a DNA fingerprint is an autoradiograph that contains at least five essential lanes.The markers are standardized DNA fragments of known size,which have been radioactively labeled.They help determine the size of the various fragments.The "control" is DNA from a source known to react posiively and reliably tothe DNA probes and shows whether the test has worked as expected.In crime cases the experimental lanes have samples from the victim,the defendant,and the crime scene.

Two variants of DNA fngerprinting have been used: single locus probing (SLP) and multiple-locus probing (MLP). In SLP,each probe is specific for a single site,that is a single locus in the genome. Because humans are diploid,each SLP probe normally gives rise to two bands from each person,provided that the chosen locus shows substantial allelic variation. Occasionally persons will be homozygous and show only a single band.For full identification using SLPs it is necessary to run several reactions,each using a different SLP probe. Multilocus probes bind to multiple sites in the genome and consequently generate multiple bands from each individual. Because it is not known which particular band comes from which particular locus,interpretation is difficult.Furthermore statistical analysis is impractical,and data cannot be reliable standardized for reference.In practice,fingerprints generated by MLP must be directly compared with others run on the same gel.

Historically MLP was used before SLP.However,SLPs uses smaller amounts of material and are easier to interpret and compare.Statistical analysis and population frequencies are possible using SLP data.Consequently,MLP metods have largely been displaced by SLP analysis [15]. In addition to preparing DNA for fingerprinting,PCR may be used to generate DNA segments for direct comparison by DNA sequencing or hybridization.PCR is especially useful for amplifying small regions of DNA with high -person to person variability.If the sequences of two samples match in several highly variable regions,they are probably from the same person. (15).In this approach DNA from a forensic sample is amplified by PCR and compared with DNA from the suspect.For hybridization,spots of DNA samples are bound to a membrane and tested for binding a DNA probe that is tagged with a fluorescent dye (radioactive probes were used in early work).In such dot blots,the probe either binds or doesn't bind,so any spot is either positive or negative. Alternatively,segments of DNA that have been amplified can be fully sequenced.DNA fingerprinting relies on the unique pattern found in different individuals when a series of DNA fragments is separated according to length.The polymerase chain reaction (PCR) is now used to generate the DNA fragments for DNA fingerprinting [15].

Teeth are important evidentiary material in forensic cases since they are more resistant to postmortem degradation as well as extremes of environmental conditions.Teeth are also easy to transport and serve as a good source of DNA. Comparisons of antemortem dental records with skeletal remains provide useful means to identify individuals; even in a mass grave.In affluent societies, dental records may be decisive in determining the identity of individual victims.However,in less affluent communities,and these are more likely tobe involved in human rights abuses leadng to mass murder,dental records are unlikely to be available. In this situation the only option for identification is DNA analysis [16]. It is possible to discriminate one individual from all others with a high level of confidence by starting with only $1 \mathrm{ng}$ or less of target DNA,whereas the amount of DNA that can be recovered from molar teeth with pulp volumes of 0,023-0,031 cc is nearly $15-20 \mathrm{mg}$. In a study by Pötsch et al. the total production of genomic DNA obtained from a dental sample ranged from 6-50ug DNA.The results were obtained from DNA extracted from the dental pulp and did not show any difference when compared to the patterns obtained from DNA extracted from blood samples or available lung tissues [3].

Remualdo evaluated the PCR amplification of DNA retrieved from teeth subjected to heat (200 degrees Celcius, $400 \mathrm{~d}$ C,500d C and $600 \mathrm{~d}$ C) during 60 minutes,testing three different extraction methods (organic,ammonia acetate/isopropanol and silica).Using the organic method for genomic DNA extraction $50 \%$ of samples subjected to burning were amplfied,but only at lower temperatures (200d C and 400d C).At higher temperatures (500d C and $600 \mathrm{~d}$ C) the isopropanol/ammonia acetate extraction yielded better results,mainly for extraction of mitochondrial DNA (mtDNA)-(17). Mitochondrial DNA can be sourced from dentine powder and also via dentine in the case of root-filled tooth [18].

\section{Methods of Dental DNA Fingerprinting}

\section{RFLP}

Restriction fragment length polymorphism (RFLP) was the first DNA profiling technique inexpensive enough to see widespread application.RFLP analysis was an important test in genome mappng,localiztion of genes for genetic disorders,determination of risk of disease and paternity testing.Due to the rise of inexpensive DNA sequencing technologies RPLF is now becomng largely obsolete,except in developing countries.As mentioned 
above,special enzymes,so called restrictive endonucleases cleaves the DNA like scissors at specific sites,each recognizing a particular sequence.These DNA scissors are specifically chosen to cut DNA at sites which are not found within the sequence of "tandem repeats" rather than conserved less variable regions.The cut fragments will contain variable number of tandem repeats (VNTRs) of varying lengths,there by producng DNA fragments of various sizes.The VNTR testing,which may present short repeated sequences of intermediate size,is rarely used in forensic analysis due to the poor quality DNA provided with this method.

\section{PCR methods}

PCR is used to amplify the amount of DNA material available,as mentioned before [15]. To carry out the reaction special enzymes and DNA primers are required.These primers are like known comstant sections of DNA but not labeled.They are designed to know constant sections of DNA at the ends of variable regions to be amplified.The principle of PCR is that the DNA is capable of duplicating itself.This is done by unwinding the strands of DNA and each strand acts as a template for synthesis of a new strand.By PCR technique one can amplify specific DNA segments dependent on the primer deployed.The standard PCR reaction runs through 30 cycles in a couple of hours which resultsin amplification of the original by over 109 times [19].The DNA found can be genomic (found in the nucleus) and mtDNA(in the mitochondria).The teeth are an excellent source of genomic and mtDNA because PCR analyses allow comparing the collected postmortem samples to known antemortem samples or parental DNA [18]. Main advantage of mtDNA is the high number of copies per cell (from hundreds to thousands of organelles).

\section{STR Analysis}

Short Tandem Repeat (STR) analysis is one of the most useful methods in molecular biology,which is used to compare specific loci of DNA from two or more samples.A short tandem repeat is a microsatellite consisting of a unit of two to thirteen molecules repeated hundreds of times in a row on the DNA strand [20]. It is a frequent and routinely used marker in forensics. STRs have a high power of individual discernment because of their high standards of polymorphic informative content.The nonoverlapping size of the alleles from different contributors serves to distinguish them. Currently they are detected by fluorescent detection methods. STR serves as the standad for the combined DNA index system ( CODIS). The FBI (Federal Bureau of Investigation) has chosen 13 definite STR loci which are together refered to as CODIS markers and the sex amelogenin marker.It is said that the likelihood that any two individuals would have identical patterns with this system is 1 in 250.000.000.000.000 [21]. STR was used on 45 DNA samples from teeth obtained from unidentified bodies buried in 1995 and exhumed in 2000,and dental pulp showed strongest PCR amplification signals [22].

\section{Mitochondria DNA analysis}

When the sample lacks nucleus DNA is extracted from mitochondria.Silva and Passos in 2002 stated that mtDNA analysisi can be used for ancient tissues like bone,hair and teeth,where analysis of nuclear DNA cannot be done [23]. High molecular weight mtDNA are obtained from teeth,especially in degraded remains [24]. Every child has he same mtDNA as its mother because mitochondrion of the embryo is from the mother's egg while genomic DNA is from fathers sperm.It is thus a valuable test in identifying missing persons by comparing mtDNA of unidentified remains with that of a possible maternal relative [25]. The technique is expensive as it is performed by direct sequencing of nitrogenous bases and prvides only lmited information as it is primarily matrilineal.

\section{Analysis of Y- chromosome}

It involves targeting of the polymorphic region of the $\mathrm{Y}$ chromosome (Y-STR) using primers. As the Y chromosome is passed to the son from his father,analysis of markers on the chromosome helps in sketching relationships among males [26].

SNP: SNP,or single nucleotide polymorphism is a detection technique to scan for new polymorphisms and to determine the allele(s) of a known polymorphism in target sequences [27]. SNP techiques provide valuable information on descent,sex,evolution and is highly automated [28,29]. The Indian Ocean tsunami of 26 december 2004 created major challenges for forensic identification of dead bodies.DNA profiling were useful in identification of those bodies where other dental procedures have been unsuccessful [30].

\section{Recent technologies in genetic identification}

Microarray techniques: The nucleic acids of the target are hybridized to hgh-density microarrays containing several thousand oligonucleotides immobilized on chips or beads (29). Many commercial platforms are available for SNP analysis.E.g. Illumna and Affymetrix.DNA analysis using this technology is used in forensic testing for sequencing and resequencing,paternity testing,SNP genotyping and identification of the individual [31].

Next generation genome sequencing: Next generation genome sequencing permits analysis of several hundred loci or even the entire genome by producing enormously parallel sequencing [32-35]. Amplification or cloning of the sequenced DNA fragments is automated and provided with a reading process.Next generation genome sequencing platforms available are Illumina genomic analyzer,Roche 454 genome sequencer and ABI Sequencing by Oigonucleotide Ligation and Detection NGS permits analysis of copy number variants (CNVs) and other structural rearrangements. Next generation sequencing can be used for both genome and trancription analysis.In genome analysis it permits the high-quality variant calling for SNPs,insertions and deletions,and allows the analysis of CNVs and other structural rearrangements. 


\section{Conclusion}

DNA fingerprinting has revolutionized the concept of identiication.Meanwhile clinical observation of available medical and dental patient records remains the gold standard for forensic pathology. DNA analysis is now the greatest forensic tool used in forensics.Of the three main kinds of DNA fingerprints,RFLP,VNTR and STR, the most commonly used is STR.RFLP and VNTR require a lot of DNA,which is usually very difficult to find at the scene and often the DNA fragments being analyzed are too long to amplify via a PCR.STR,on the other hand, uses short sections of DNA,which are ideal for running a PCR,Additionally,STR analysis does not require the hybridization to a DNA probe.New techniques as the microarray technques [36] and next generation genome sequencing [37] will stimulate dental forensics and identification further.

\section{References}

1. Betsch DF DNA Fingerprinting in Human Health and Disease. Biotechnlogy Training Program, Iowa State University Office of Biotechnology.

2. Higgins D, Austin JJ (2013) Teeth as a source of DNA for forensic identification of human remains: A review Sci Justice 53(4): 433-441.

3. Pötsch L, Meyer U, Rothschild S, PM Schneider, Ch Rittner (1992) Application of DNA techniques for identification using human dental pulp as a source of DNA. Int J Legal Med 105(3): 139-143.

4. Sweet D (2001) Why a dentist for identification? Dent Clin North Am 45(2): 237-251.

5. Smith BC, Fischer DL, Weedn VW, Warnock GR, Holland MM (1993) A systemic approach to the sampling of dental DNA. JForensic Sci 38(5): 1194-1209.

6. Sweet D, Hildebrand D, Philips D (1999) Identification of skeleton using DNA from teeth and a PAP-smear. J Forensic Sci 44(3): 630-633.

7. Sweet D, Hildebrand D (1998) Recovery of DNA from humn teeth by cryogenic grinding. Forensic Sci 43(6): 1199-1202.

8. Jeffrey AJ, Wilson V, Thein SL (1985) Hypervariable 'minisatelite' regions in human DNA. Nature 314: 67-73.

9. Dodd BE (1985) DNA fingerprinting in matters of family and crime. Nature 318(6046): 506-507.

10. Saiki RK, Scharf S, Falcona F, Horn GT, Erlich HA, et al. (1985) Enzymatic amplification of ss-globin sequences and restriction site analysis for diagnosis of sickle cell anaemia. Science 230(4732): 1350-1364.

11. Mullis KB, Falcona FA (1987) Specific synthesis of DNA in vitro via a polymerase-catalyzed chain reaction. Methods Enzymol 155: 335-350.

12. Schwartz TR, Schwartz EA, Mieszerski L, McNally L, Kobilinsky L (1991) Characterization of DNA obtained from teeth subjected to various environmental conditions. J Forensic Sci 36(4): 979-990.

13. Sweet DJ,Sweet CH (1995) DNA analysis of dental pulp to link incinerated remains of homocide victim to crime scene. J Forensic Sci 40(2): 310314.

14. Girish KL, Rahman FS, Tippu SR (2010) Dental DNA fingerprinting in identification of human remains. J Forensic Dental Sci 2(2): 63-68.

15. Clark DP, Pazdernik J ( 2016) Forensic Molecular Biology. Biotechnology $2^{\text {nd }}(\mathrm{edn})$. Elsevier publications.

16. Trent RJ (2005) Forensic Medicine and Science. Molecular Medicine. $3^{\text {rd }}$ (edn.). Elsevier Pubications.
17. Remualdo VR (2004) Assessment of three methods of extraction of DNA of teeth of humans subjected to heat (dissertation).

18. Shiroma CY, Fielding CG, Lewis JA, Gleisner MR, Dunn KN (2004) A minimally destructive technique for sampling dentin powder for mitochondrial DNA testing. J Forensic Sci 49(4): 791-795.

19. Brannon RB, Kessler HP (1999) Problems in mass disaster dental identification: A retrospective review. J Forensic Sci 44(1): 123-127.

20. Sakari SL, Jimson S, Masthon KM, Jenita Jacobina (2015) Role of DNA profiling in forensic odontology. J Pharm Bioallied Sci 7( Suppl 1): S138-S141.

21. Rosenberg LE, Rosenberg DD (2012) Personalized Genetics and Genomics. In: Human Genes and Genomes $1^{\text {st }}($ edn.). Elsevier pp.446.

22. Malaver PC, Yunis JJ (2003) Different dental tissues as source of DNA for human identification in forensic cases. Croat Med J 44(3): 306-309.

23. Silva LA, Passos NS (2002) DNA Forense. Collection of biological samples at crime scenes to study DNA.Maceio (Ed.). UFAL.

24. Koyama H, Isawa M, Ohtani S, Ohira H, Tsuchimochi T, et al. (2002) Personal identification from human remains by mitochondrial DNA sequencing. Am J Forensic Med Pathol 23(3): 272-276.

25. Budowle B, Dizinno JA, Wilson MR Interpretation Guideliines for mitochondrial DNA sequencing.

26. Zhongh H, Shi H, Qi XB, Xiao CJ, Jin L, et al. (2010) Global distribution of Y-chromosonme haplogroup $\mathrm{C}$ reveals the prehistoric migration routes of African exodus and early settlement in East Asia. J Hum Genet 55(7): 428-435.

27. Budowle B (2004) SNP typing strategies. Forensic Sci Int 2(146): S139-S142.

28. Kwok PY, Chen X (2003) Detection of single nucleotide polymorphisms. Curr Issues Mol Biol 5(2): 43-60.

29. Sobrino B, Brion M, Carrucedo A (2005) SNPs in forensic genetics: A review on SNP typing methodologies. Forensic Sci Int 154(2-3): 181194.

30. Hirsch C, Brondolo T, Butcher B (2005) Report to Dr Surachai,Minister of Public Health,Thailand and Dr William Aldis, WHO representative to Thailand World Health Organization:Assessment of victim identification operations: Thailand tsunami disaster. City of New York Office of Chief Medical Examiner, New York, USA p. 11.

31. Li L, Li CT, Li RY, Liu Y, Lin Y, et al. (2006) SNP genotyping by multiplex amplification and microarrays assay for forensic application. Forensic Sci Int 162(1-2): 74-79.

32. Da Silva RH, Sales-Peres A, De Oliviera RN, De Oliveira FT, Sales-Peres $\mathrm{SH}$ (2007) Use of DNA technology in forensic dentistry. J Appl Oral Sci 15(3): 156-161.

33. Tucker T, Marra M,Friedman JM (2009) Massively parallel sequencing: The next big thing in genetic medicine. Am J Human Genet 85(2): 142154.

34. Li C, Qi B, Ji A, Lan Hu,Xiulan Xu (2009) The combination of single cell micromanipulation with LV-PCR system and its application in forensic science. Forensic Sci Int Genet Suppl Ser 2(1): 516-517.

35. Hakismendy O, NG PC, Straasberg RL, Wang X, Stockwell TB, et al. (2009) Evaluation of next generation sequencing platforms for population targeted sequencing studies. Genome Biol 10(3): R32.

36. Mital KL, Etzier FM (2017) Adhesion in Pharmaceutical. Biomedical and Dental Fields, Wiley Publications.

37. Yang Y, Xie B, Yan J (2014) Application of Next-Generation Sequencing Technology in Forensic Science. Genomics Proteonomics Bioinformatics 12(5): 190-197. 
This work is licensed under Creative Commons Attribution 4.0 License

To Submit Your Article Click Here:

Submit Article

DOI: 10.32474/MADOHC.2018.02.000143

\section{Modern Approaches in Dentistry \\ MADOHC and Oral Health Care}

\section{Assets of Publishing with us}

- Global archiving of articles

- Immediate, unrestricted online access

- Rigorous Peer Review Process

- Authors Retain Copyrights

- Unique DOI for all articles 